\title{
ENHANCED GROWTH OF THE MACROPHYTE Juncus bulbosus IN S NORWEGIAN LIMED LAKES. A REGIONAL SURVEY.
}

\author{
T. E. BRANDRUD ${ }^{1} \&$ J. G. M. ROELOFS ${ }^{2}$ \\ 1 Norwegian Institute for Water Research, P.O. Box 173, Kjelsås, 0411 Oslo, Norway \\ 2 Department of Ecology, Section Environmental Biology, Catholic University of \\ Nijmegen, Toernooiveld, 6525 ED Nijmegen, The Netherlands
}

\begin{abstract}
The effects of liming on the aquatic macrophyte vegetation have been investigated in $\mathrm{S}$ and SW Norway. In the western part of the study area, Juncus bulbosus was considerably more frequent in the limed than in the unlimed lakes, whilst in the eastern part there were no such differences, and the $J$. bulbosus populations were generally not so vital. In some southwestern areas a luxuriant and massiv nuisance growth of Juncus bulbosus in the depth zone 0-4 m was recorded. The most vital plants produced up to $1 \mathrm{~m}$ long annual shoots, and developed extensive, dense and vital surface mats in shallow areas (depth zone 0-3 m) after 4-5 years. The original isoetid vegetation had disappeared in the areas of dense $J$. bulbosus populations, and this development seems to be more or less irreversible. The massive $J$. bulbosus expansion is seen mainly in directly limed lakes with a sometimes visible layer of calcium carbonate on the sediment surface, but enhanched growth has been observed also in lakes downstream liming. The massive expansion is believed to be due to an increase of $\mathrm{CO}_{2}$ and ammonium in the sediment pore water, combined with a mild climate with a very high precipitation. In many areas the liming has led to an increase in species diversity, and a (re-)establishment of some acid-intolerant species such as Myriophyllum alterniflorum and Potamogeton spp.
\end{abstract}

Key words: liming, lakes, S Norway, juncus bulbosus, nuisance growth

\section{Introduction}

The grass-like, extremely polymorphic aquatic macrophyte Juncus bulbosus L ( $=J$. supinus Moench) is normally regarded as an acidophilic species, with increased growth after acidification (Grahn, 1977, Roelofs, 1983). The species has an oceanic distribution and is one of the most frequent and widespread aquatic plants in S and W Norway, and it was occurring in almost every lowland lake of this area even before acidification (Brandrud \& Mjelde, 1993). The species normally has a rosette growth with only short vertical shoots, and dense stands are usually found only in sheltered bays or inlet/outlet areas as well as in regulated, gently flowing rivers where massive growth of the species can become a real nuisance (Brandrud, 1990). Recently an extensive and very aggressive growth of $J$. bulbosus has also been observed in limed lakes of SW Norway (Persson, 1994, Roelofs et al., 1994). This is in contrast to the results from Sweden, where small changes in the $J$. bulbosus populations are reported after liming (Eriksson, 1988). To study the extension of the $J$. bulbosus expansion after liming, a regional study of vegetation changes after liming has been carried out in S and SW Norway. So far results, including synoptic vegetation tables, have been published in annual reports (cf. Brandrud, 1995).

Water, Air and Soil Pollution 85: 913-918, 1995.

(C) 1995 Kluwer Academic Publishers. Printed in the Netherlands. 


\section{Material and Methods}

Field work was carried out in S and SW Norway during July-August 1992-1994, and results from 55 lakes in the counties of Rogaland (23 lakes), Vest-Agder (20) and Aust-Agder (12) are included in the present study. Of these lakes 20 were unlimed reference lakes, mainly strongly acidified ( $\mathrm{pH}=4.5-5.0$ ), 27 lakes were directly limed, and 8 lakes were indirectly influenced by upstream liming. The distribution, composition and structure of the aquatic vegetation were surveyed. In each lake, the abundance of the species was scored according to a five-step, subjective scale. In addition, the percentage of the colonizable littoral zone along the lake with extensive growth of $J$. bulbosus was estimated, that is areas with tall plants $(>50 \mathrm{~cm})$ and a high coverage $(>50 \%)$ in the optimal depth zone $1-2 \mathrm{~m}$. Furthermore, the presence of well-developed surface mats of $J$. bulbosus plants coming from the depth zone $1-2(-3) \mathrm{m}$ was noted.

\section{Results}

A considerably higher density and abundance of Juncus bulbosus (= J. supinus) were found in limed lakes than in unlimed, acidified lakes in Rogaland and Vest-Agder, S/SW Norway (Figure 1). The highest density was seen in lakes directly limed during more than 4-5 years. Lakes indirectly limed (by liming upstream) normally had only slightly denser populations than the unlimed ones. Although the species was present in every lake studied, dense $J$. bulbosus stands had developed in only $16.5 \%$ of the littoral zone in the unlimed, acidified lakes (Figure 1).

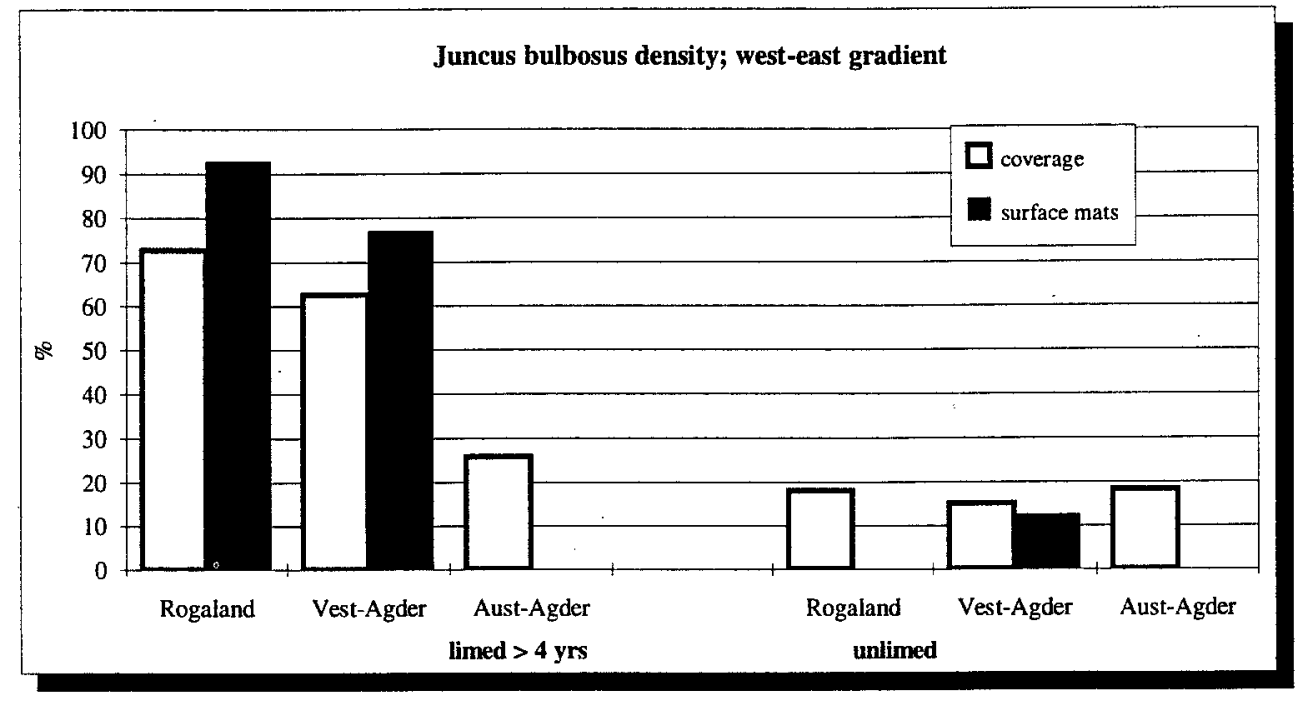

Fig. 1. Density of Juncus bulbosus in various categories of limed and unlimed lakes in S-SW Norway, the counties of Vest-Agder and Rogaland. coverage $=\%$ of (colonizable) littoral zone with dense populations of $\mathbf{J}$. bulbosus (MVs). surface mats $=\%$ of localities in each category with surface mats of $J$. bulbosus (produced by plants arising from $1-3 \mathrm{~m}$ depth). 
Also the manner of growth was different in the limed and unlimed lakes: Tall growing columns with dense surface mats were observed in $89 \%$ of the long-term limed lakes, but only in $6 \%$ of the unlimed ones (Figure 1).

After liming, J. bulbosus produced $2-3 \mathrm{~m}$ tall columns, consisting of up to $1 \mathrm{~m}$ long, annual shoots, successively branching and reaching surface after ca. 3-5 years. In some lakes these fast-growing plants produced almost compact stands from 0-4 meters depth, and only fragments of the original isoetid vegetation were left in labyrinthic openings in the $J$. bulbosus populations. After reaching surface the columns developed extensive, confluent and very vital surface mats. These floating mats consist of a subsurface layer of densely interwoven shoots and roots and a surface of short, erect, emerged shoots, reminiscent of those of emergent shoreline, terrestrial populations. Many of the surface mats have survived during the investigation period (1992-1995), in spite of varying winter climate, the winter of $1993 / 94$ causing a permanent ice cover in all lakes.

A regional west-east gradient in the $J$. bulbosus development was also observed, with a much lower coverage and no development of surface mats in the limed lakes of the more eastern, acidified areas (Aust-Agder; Figure 2). In Aust-Agder the density of J. bulbosus was fairly similar in unlimed and limed lakes, and vital, tall $J$. bulbosus plants were observed mainly in inlet/outlet areas and in some humic lakes with soft, organic bottoms.

In most areas the highest species diversity was observed in the limed lakes, especially long-termed limed lakes (Figure 3). The group of elodeids played an increasing role after liming, and the species Myriophyllum alterniflorum DC., Potamogeton spp. and Utricularia vulgaris $\mathrm{L}$. were recorded almost exclusively in the latter situation.

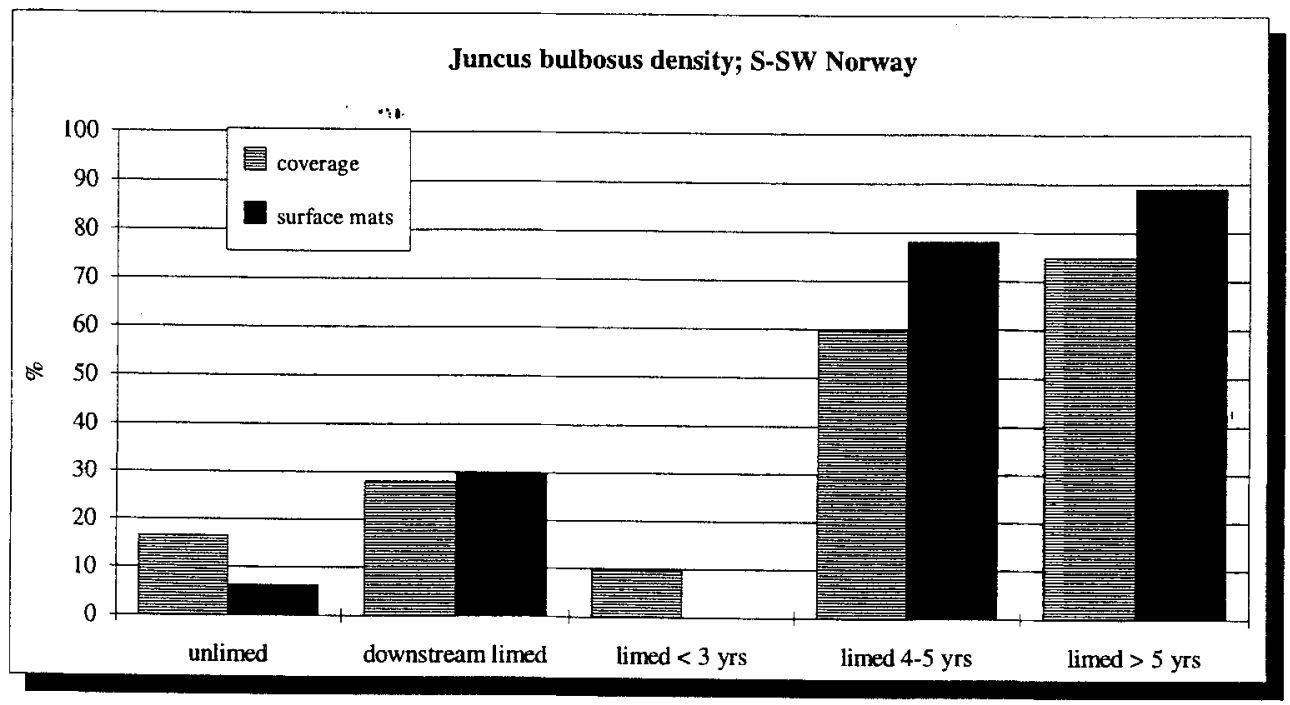

Fig. 2. Regional variation. Density of Juncus bulbosus in lakes limed $>4$ years and in unlimed, acidified lakes along a west-east gradient in S Norway, including the counties of (from west) Rogaland, Vest-Agder and AustAgder. coverage $=\%$ of (colonizable) littoral zone with dense populations of $\mathbf{J}$. bulbosus (MVs). surface mats $=\%$ of localities in each category with surface mats of J. bulbosus (produced by plants arising from 1-3 m depth). 


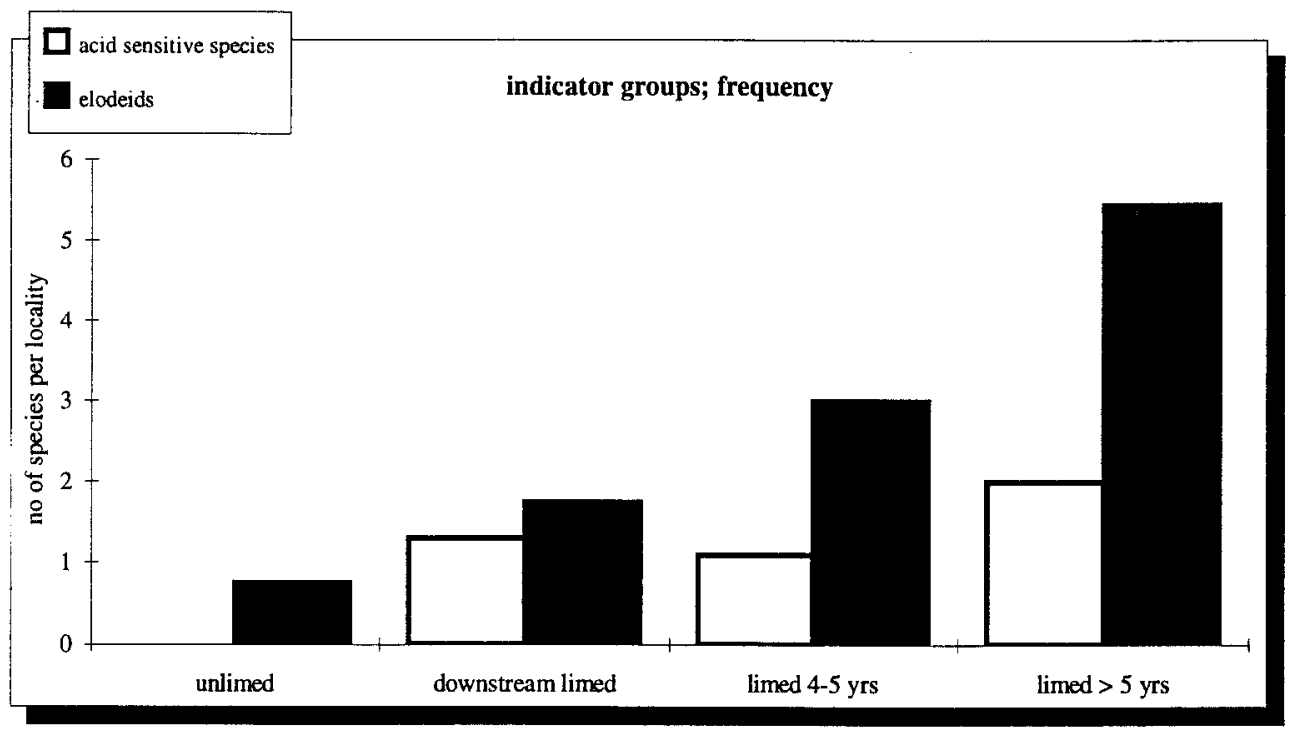

Fig. 3. Categories of species with increasing frequency after liming. acid sensitive species = species supposed sensitive to acidification, not occurring in the unlimed, acidified lakes (Myriophyllum alterniflorum, Potamogeton spp. and Utricularia vulgaris). Material from Vest-Agder.

\section{Discussion}

Except for the publication of Roelofs et al. (1994) from Sokndal, SW Norway, the phenomenon of substantially increased Juncus bulbosus growth after liming is previously not reported, and has never been documented on a regional scale. It seems mainly to be an oceanic phenomenon, with a strict border to the east in Norway. Massive growth is observed also in the few limed lakes in The Netherlands (pers. obs.). A similar massive growth of $J$. bulbosus after liming is not known from Sweden, but an increase in the populations has been observed in some lakes (H. Hultberg, pers. comm., Grahn \& Sangfors, 1988, Eriksson, 1988). Eriksson (1988) found also examples of a slight decrease in $J$. bulbosus populations in Swedish lakes after liming.

The extremely vital growth of $J$. bulbosus, with plants reaching surface from 2-3 meters depth, and producing dense surface mats, seems to be unique for limed lakes, and it is not observed in unmanipulated lakes. Very high production values of $J$. bulbosus were found in the areas of massive growth at Sokndal, Rogaland, SW Norway. In limed lakes with dense vegetation, a $J$. bulbosus biomass of $1130 \mathrm{~g} \mathrm{DW} \mathrm{m}^{-2}$ (MV) was measured, compared to 58 $\mathrm{g} \mathrm{DW} \mathrm{m}^{-2}$ in comparable, adjacent unlimed lakes (Roelofs et al., 1994).

The fact that the most extreme development of $J$. bulbosus has occurred in lakes with a visible deposit of lime on the sediment surface, indicates that the expansion can be related to changes in the sediment after (over)liming. The chemistry of water and sediment pore water has been investigated in the area of Sokndal, Rogaland since 1993 (cf. Roelofs et al., 1994). Significantly higher levels of ammonium and $\mathrm{CO}_{2}$ have been found in the pore water of the limed lakes with massive $J$. bulbosus growth, and this corresponds with the results from laboratory experiments with $J$. bulbosus. According to these experiments, a rapid and 
substantial growth of $J$. bulbosus depends on high concentrations of $\mathrm{CO}_{2}$ and ammonium (Schuurkes et al., 1987).

Expansion of $J$. bulbosus after acidification is well-known from The Netherlands (Roelofs, 1983) and has been reported also from some lakes in Sweden (Grahn, 1977, Svedäng, 1990). An increase of J. bulbosus and submerged Sphagnum was postulated on a regional scale after acidification as part of the oligotrophication hypothesis introduced by Grahn et al. (1974). However, in Norway there has been no or little increase in these vegetation elements after acidification (Brandrud \& Mjelde, 1993), a fact that probably has to do with extremely oligotrophic conditions, low decomposition rates, and low $\mathrm{CO}_{2}$ levels in the acidified clearwater lakes in S Norway. Liming, on the other hand, leads to a eutrofication of the sediment (Roelofs et al., 1994), and also to a temporarely increased $\mathrm{CO}_{2}$ production in the water, when $\mathrm{CaCO}_{3}$ is mixed with very acid water, and therefore causes at least temporarely optimal conditions for J. bulbosus.

The long-term effect of liming on vegetation community structure, species diversity, and nuisance growth is difficult to assess. $J$. bulbosus-dominated lakes that have been limed for 10-12 years still have high growth rates and intact surface mats. Even if the conditions for $J$. bulbosus should become less optimal in time due to increasing alcalinity and less $\mathrm{CO}_{2}$ available, the development seems to be largely irreversible. The original isoetid vegetation gradually disappears and the compact $J$ uncus stands produce a soft, organic sediment in which the isoetid species are not able to germinate (Roelofs, unpublished).

The strong differences in $J$. bulbosus growth response to liming in the geologically very similar western and eastern areas of S Norway (cf. Holtedal, 1960) are remarkable, and could indicate that many lakes in these systems are balancing on a threshold value for aggressive growth. Probably this aggressive growth is induced by a combination of liming and certain climatic conditions. The most vital and luxuriant growth seems to have occurred in the years around 1990, when the climate was milder than normal, with a series of ice-free winters and a very high precipitation, especially in SW Norway. These conditions are probably optimal for $J$. bulbosus, providing a very long growing season, rapid reacidification of the limed lakes and a high $\mathrm{CO}_{2}$ production.

The negative effects and sometimes lack of reversibility of the acidified systems after liming have been little focused in the literature so far. The ecosystem effect research has emphasized mainly the detoxification of the water and the response of fish and invertebrates (cf. Henrikson \& Brodin, 1995). However, besides the neutralization and detoxification liming also represents a considerable input of inorganic carbon into lakes where this might be a limiting factor. Many macrophytes are limited by inorganic carbon in oligotrophic lakes (Wetzel et al., 1985), and therefore, an expansion of certain elements of water plants is to be expected. In SW Norway, the expansion of a $\mathrm{CO}_{2}$ limited plant is seen $(J$. bulbosus). In the case of long term liming with a build up of alcalinity, one will probably see more examples also of expansion of $\mathrm{HCO}_{3}$ limited (oligotrophic) species, such as Myriophyllum alterniflorum. In Norway an extensive expansion of $M$. alterniflorum has until now been observed in one lake limed during 10 years, and massive expansion of this species has also been observed in long-term limed lakes in Sweden (Grönlund, 1987, Dixon et al., in the present publication). 


\section{Acknowledgements}

We wish to thank M. Mjelde, NIVA, Oslo for assistance during field work, and The Directorate for Nature Management, Trondheim for financial support.

\section{References}

Brandrud, T.E.: 1990, Proceedings EWRS 8th Symposium on Aquatic Weeds, Uppsala 1990, 55-60.

Brandrud, T.E.: 1995, [in:] Romundstad, A.J., Directorate for nature management Rep. XX-1995 (in print.). Trondheim.

Brandrud, T.E and Mjelde, M.: 1993, Norwegian Institute for Water Research Rep. 2936, Oslo.

Eriksson, F.: 1988, Information från Sötvattenlaboratoriet Drottningholm Rep. 9/1988. Stockholm.

Grahn, O.: 1977, Water, Air \& Soil Pollution 7, 295-305.

Grahn, O., Hultberg, H. Landner, L.: 1974, Ambio 3, 93-94.

Grahn, O. \& Sangfors, O.: 1988, National Swedish Environmental Protection Board. Rep. 3426, 281-308.

Grönlund, T.: 1987, Fiskerivård 3, 28-29.

Henrikson, L. \& Brodin, Y.W.: 1995, Liming of acidified surface waters. A Swedish synthesis. Springer.

Holtedahl, O.: 1960 (ed.), Norw. Geol. Survey 208, 1-540.

Persson, U.: 1994, Fylkesmannen i Rogaland, miljøvernavdelingen, Environm. Rep. 1-1994, Stavanger.

Roelofs, J.G.M.: 1983, Aquat. Bot. 17, 139-155.

Roelofs, J.G.M., Brandrud, T.E. \& Smolders, A.J.P.: 1994, Aquat. Bot. 48, 187-202.

Schuurkes, J.A.A.R., Elbers, M.A., Gudden, J.J.F. and Roelofs, J.G.M.: 1987, Aquat. Bot. 28, 199-226.

Svedäng, M.U.: 1990, Aquat. Bot. 37, 123-138.

Wetzel, R.G., Brammer, E.S., Lindström, K. \& Forsberg, C.: 1985, Aquat. Bot. 22, 107-120. 